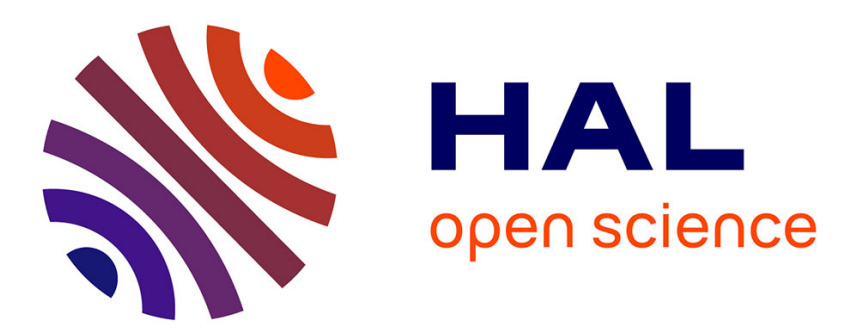

\title{
Morphological Segmentation of Building Façade Images
}

Jorge Hernandez, Beatriz Marcotegui

\section{To cite this version:}

Jorge Hernandez, Beatriz Marcotegui. Morphological Segmentation of Building Façade Images. 16th IEEE International Conference on Image Processing (ICIP), Nov 2009, Le Caire, Egypt. pp.4029-4032, 10.1109/ICIP.2009.5413756 . hal-00834428

\section{HAL Id: hal-00834428 \\ https://hal-mines-paristech.archives-ouvertes.fr/hal-00834428}

Submitted on 15 Jun 2013

HAL is a multi-disciplinary open access archive for the deposit and dissemination of scientific research documents, whether they are published or not. The documents may come from teaching and research institutions in France or abroad, or from public or private research centers.
L'archive ouverte pluridisciplinaire $\mathbf{H A L}$, est destinée au dépôt et à la diffusion de documents scientifiques de niveau recherche, publiés ou non, émanant des établissements d'enseignement et de recherche français ou étrangers, des laboratoires publics ou privés. 


\title{
MORPHOLOGICAL SEGMENTATION OF BUILDING FAÇADE IMAGES
}

\author{
Jorge Hernández and Beatriz Marcotegui \\ Mines ParisTech \\ CMM- Centre de morphologie mathématique \\ Mathématiques et Systèmes \\ 35 rue St Honoré 77305-Fontainebleau-Cedex, France
}

\begin{abstract}
In this paper, we describe an automatic method for segmentation of building façade images. First, individual façades are isolated from general city block images. This step is based on accumulation of directional color gradients, assuming that façade structures are aligned. Then sky region is detected based on segmentation approach and color marker extraction. Finally, the images are split in floors using directional color gradient accumulation, as well. Our approach introduces several morphological filters to augment the robustness to problems such as: textured balconies, some specular reflections of the bright windows and small obstacles in images. The experimental results show the performance of our approach.
\end{abstract}

Index Terms - Mathematical morphology, façade segmentation, urban modeling

\section{INTRODUCTION}

3D urban environment modeling becomes a fundamental part in a growing number of geo-applications as e.g Google Earth, Microsoft Virtual Earth, IGN - Geoportail 3D, etc. The main approaches to model cities are based on coarse modeling, for instance: polyhedral representation, main walls, roof planes and ground planes. Nevertheless, recent research frameworks try to analyze building façades in real images. This analysis extracts and reconstructs windows, doors and ornaments to provide rich information of the buildings and to add visual realism. Furthermore, the reconstruction of façades is a hard problem, given the large variety in their appearances and structures $[1,2]$. The building façade analysis has been widely studied in the literature. In general, the methods use rectified and cropped images. Lee and Nevatia in [3] and Wang et al. [2] developed a method to detect windows from street level images of isolated buildings. Müller et al. in [4] find repetitive architectural structures by using mutual information to describe

\footnotetext{
$\{$ hernandez,marcotegui $\} @$ cmm.ensmp.fr
}

a single façade image; where the façade is manually extracted.

However when we take a picture of city blocks from the street level, several problems appear to model a single façade: 1- Variations of resolution caused by perspective effects, 2- Multiple façades in images, 3- Sky information, 4- Road and sidewalk information, 5 - Ground floor; the ground floor is considered a problem due to non repetitive structures [4]. These problems are illustrated as an input image of Fig. 1.

In this paper we present an automatic method that extracts isolated façades from city block images. This segmentation facilitates the extraction of semantic/grammatical information from a single ortho-façade and an efficient grammatical modeling of façades becomes possible.

This paper is organized as follows. Section 2 describes our method. Vertical splitting in isolated façades is presented in Section 2.1. Sky detection and horizontal splitting are shown in Section 2.2 and Section 2.3, respectively. Section 3, experimental results are shown and the performance of our method is illustrated. Finally, conclusions are drawn in Section 4.

\section{SEGMENTATION OF BUILDING FAÇADES}

A block diagram and an example of the method are given in Fig. 1. The first step of our method is image rectification. We have developed an automatic rectification algorithm by using vanishing point detection via Hough transform [5].

\subsection{Vertical Splitting}

We assume that façade structures (windows, doors, balconies) are horizontally and vertically aligned [3]. For that reason, our approach is based on gradient projection analysis. For vertical splitting only horizontal gradient is used. The horizontal color gradient $\left(G_{h}\right)$ is generated by using a vertical structuring element (SE). With this 


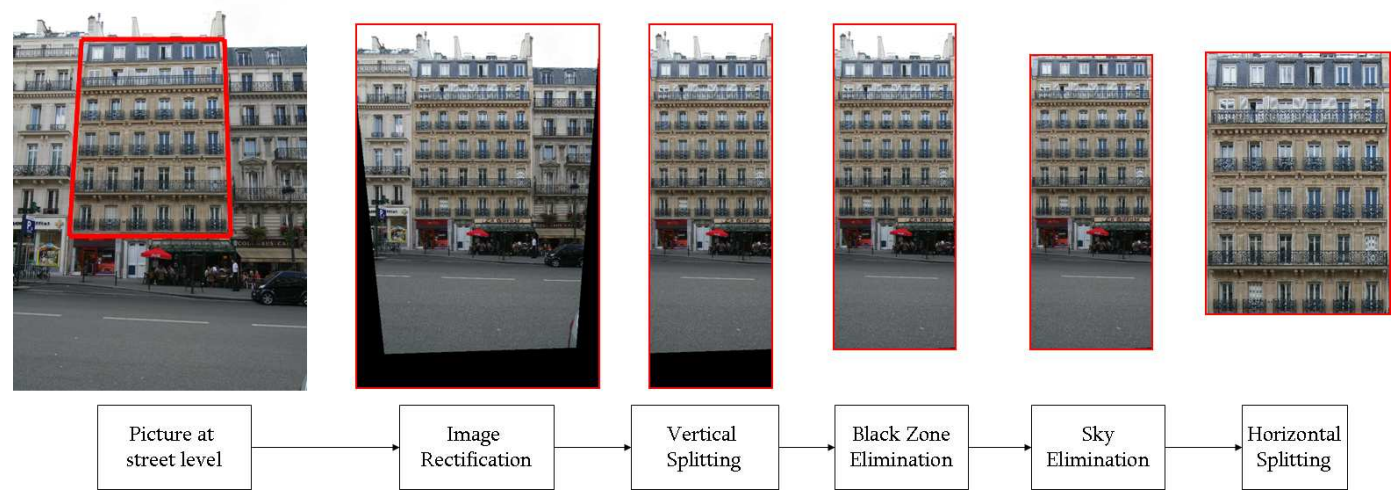

Fig. 1. Segmentation of building façade method. Input image: picture of city blocks from street level and Output required image for modelling purposes.

assumption, the approach is more robust to generated gradients by noise or spurious structures in other directions. Fig. 2(a) shows $\left(G_{h}\right)$. Afterwards, we accumulate on columns $\left(G_{h}\right)$, providing vertical projection $P_{v}\left(G_{h}\right)$.

Nevertheless, in textured façades, the gradient accumulation $P_{v}\left(G_{h}\right)$ presents two important problems: the creation of false peaks and false valleys and the reduction of dynamic between them. These problems produce an erroneous façade division. To solve this problem a filtering operation is included, before the gradient projection. We apply a directional morphological opening of $\lambda$ size. The directional opening is applied in the same direction of gradient, i.e horizontal opening for $G_{h}$ image. The size opening value is estimated using the smallest possible window size. The filtered gradient $\left(\widetilde{G_{h}}\right)$ is shown in Fig. 2(b).

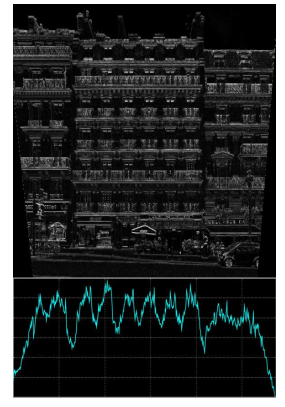

(a) $G_{h}$ and $P_{v}\left(G_{h}\right)$

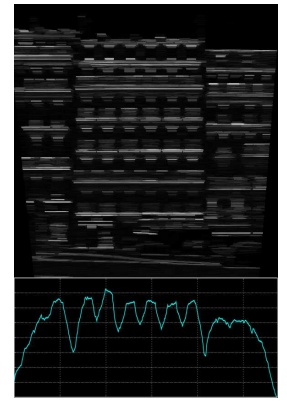

(b) $\widetilde{G_{h}}$ and $P_{v}\left(\widetilde{G_{h}}\right)$

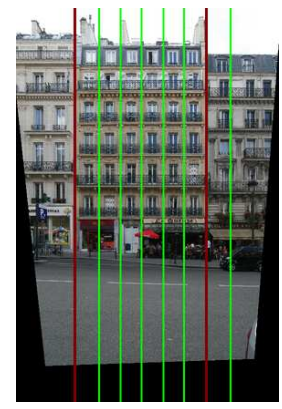

(c) Façade division
Fig. 2. (a) Horizontal color gradient and projection, (b) Filtered gradient and projection. (c) Vertical façade division.

$P_{v}\left(\widetilde{G_{h}}\right)$ profile contains peaks at windows locations and valleys within the wall. The profile is filtered by using an alternate sequential filter $(A S F)$ to allow an easy detection of the most representative maxima and minima of $P_{v}\left(\widetilde{G_{h}}\right)$. Finally, to find the façade division we use watershed $(W S)$ segmentation of inverted $A S F\left(P_{v}\left(\widetilde{G_{h}}\right)\right)$. The cost of this segmentation is very low thanks to the fact that operation is applied to profiles (1D images). Vertical division result is illustrated in Fig. 2(c).

Among found divisions, we have two division types: intra - façades and inter - façades. We can see on $P_{v}\left(\widetilde{G_{h}}\right)$ profile, inter - façade divisions have lower valuation than intra - façade divisions. This is due to the fact that there are not horizontal structures in the separation line between two buildings, while intra-façade divisions cross balcony handrails, ornaments or floor separations, leading to a higher profile valuation. Hence, to classify both division types a k-means clustering algorithm is used. We assume as initial cluster seeds, absolute minimum and maximum data value. At last, the divisions belonging to minimum seed cluster are the inter - façade separations (Fig. 2(c): red lines).

\subsection{Sky Elimination}

As a result of perspective correction, several black zones appear in the image. These zones produce some problems in sky detection and horizontal splitting. Thus, a simple method to remove top and bottom black zones is implemented.

Sky detection is a common problem in pattern recognition where the number of patents has been very significant. Sky information has been used to classify indooroutdoors scenes [6], to know the orientation of images[7] and as a marker to detect the semantic of urban images [2]. We propose a method, applied to urban images, based on connected component extraction and color information. We combine two approaches as a starting point: combination of a segmentation of connected com- 
ponents and a color marker [8]; and seed region detection to characterize the sky color [7].

Our method has the following

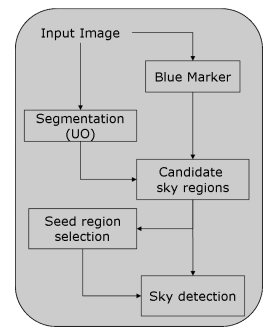
steps: First, the image is segmented by using ultimate opening (UO) operator [9]. In parallel, a marker of blue color is calculated. Hence, in the third step we extract candidate regions of the sky, based on color and position criteria. Next, a seed sky region is selected and characterized by a

Fig. 3. Sky detection process diagram.

Gaussian Model. Finally, all candidates regions whose color compatible with the computed color model are added to the sky result. These steps are translated into Fig. 3. The method is a relatively simple to detect the sky. More structured approaches $[6,7]$ are available to improve the robustness. Moreover, these methods look for all CCs of the image to select candidate regions. In our case, this is not the best solution because of window reflection problem in urban images which produces a lot of false positives. Fig. 4 shows some examples of the experimental results by demonstrating the performance of our method. We illustrate characteristic cases of the sky in urban images where our method has correctly detected it.

Subsequently to sky detection, the sky is eliminated horizontally and vertically, if it is necessary. Horizontally, we cut sky off, where horizontal sky edges have the largest number of pixels; after that a similar procedure is applied on vertical direction.
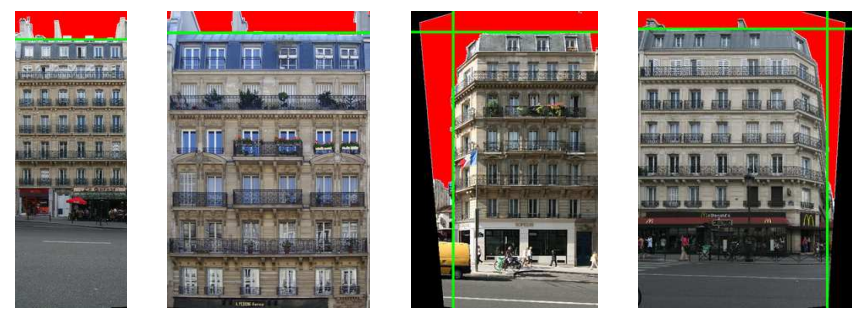

Fig. 4. Sky detection and lines of cropping images.

\subsection{Horizontal Splitting}

By using the same method of gradient projection presented in Section 2.1, a first horizontal division is carried out. In this case a vertical color gradient $\left(G_{v}\right)$ is produced by a horizontal SE (Fig. 5(a)). Then, gradient image is filtered by a vertical opening by generating $\widetilde{G_{v}}$ (Fig. 5(b)). After that, we project $\widetilde{G_{v}}$ on its perpendicular direction to create $P_{h}\left(\widetilde{G_{v}}\right)$ profile (Fig. $5(\mathrm{c})$ ).
Next, the profile is filtered by: an $A S F$ as in vertical splitting case, and a $h$-Minima operator [10]. $h$-Minima filter eliminates minima which have a depth lower than a threshold $h$. This operator is added to avoid divisions on homogeneous regions such as roads. Lastly, we use $W S$ segmentation of inverted filtered profile to find horizontal divisions.

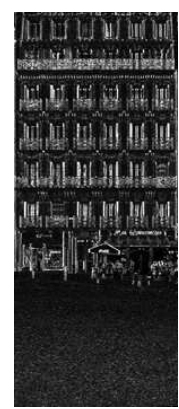

(a) $G_{v}$

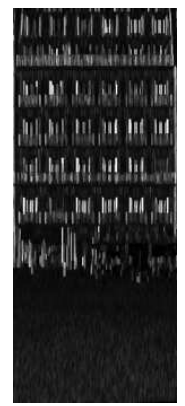

(b) $\widetilde{G_{v}}$

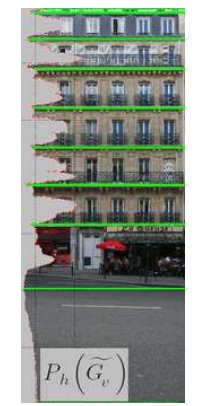

(c) $P_{h}\left(\widetilde{G_{v}}\right)$

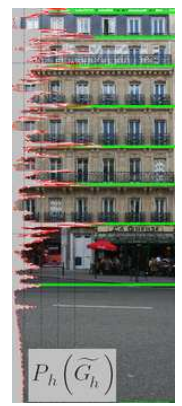

(d) $P_{h}\left(\widetilde{G_{h}}\right)$
Fig. 5. (a) Horizontal color gradient. (b) Filtered gradient. (c) Horizontal projection of $\widetilde{G}_{v}$ and horizontal façade division. (d)Horizontal projection of $\widetilde{G_{h}}$ and horizontal façade division refining.

We have found horizontal divisions thanks to window gradients (Fig. 5(b)). For that reason, floor separations are not precisely located. To solve this problem, we move the first divisions to the highest horizontal gradient $\left(\widetilde{G_{h}}\right)$ for each floor, given as a result Fig. 5(d).

In order to eliminate the ground floor and road section, we remove the last section iteratively. In this example, two sections should be removed. To determine if a division will be eliminated, we compute the difference between normalized $P_{v}\left(\widetilde{G_{h}}\right)$ and normalized $P_{v}\left(\widetilde{G_{h}}(\right.$ floor $\left.)\right)$ for each floor.

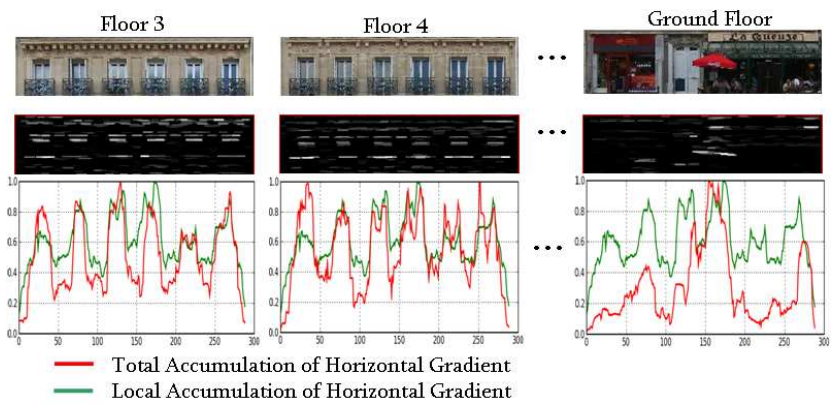

Fig. 6. Analysis of sections.

Note that the difference of a normal floor is lower than difference of ground floor (Fig. 6). This difference between dynamics is due to the gradient produced by 
windows. If the section difference is bigger than difference mean, the section is eliminated.

\section{EXPERIMENTAL RESULTS}

The presented method was tested on images acquired by uncalibrated cameras. The images correspond to approximately ten urban blocks of the 5th Paris district. Moreover, we have tested the same technique on problematic images (Fig. 7) by showing that the proposed method is robust to problems such as: textured balconies, some specularity on the windows, small obstacles (trees, flowerpots). The method presents good results on the whole dataset (all databases and result tests can be found on the following web site $\left.{ }^{1}\right)$.

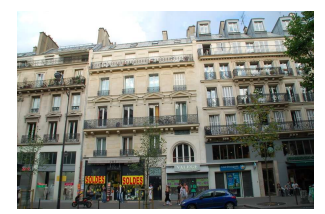

(a)

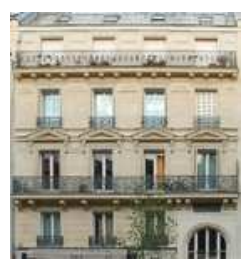

(d)

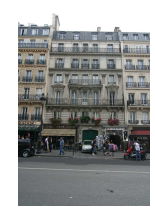

(b)

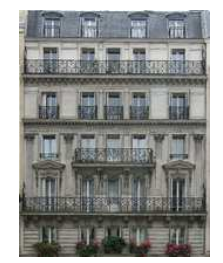

(e)

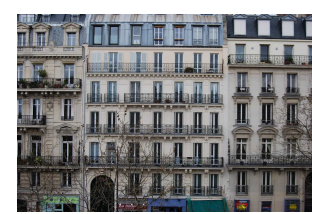

(c)

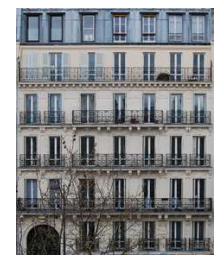

(f)

Fig. 7. Images with several obstacles (a-c) Input images (d-f) Output images

\section{CONCLUSIONS}

The major contribution of this paper is a novel method for morphological segmentation of building façade images. From an urban block picture taken from the ground level, we obtain a cropped ortho-façade image. The method is completely automatic with the same parameters for the whole dataset. Several morphological filters are added through the process, by increasing the robustness of method. The vertical and horizontal division is based on profile analysis. The profiles are created by projection of directional color gradients. Moreover, we have developed a sky detection method from urban images. The method has been designed to detect day light skies via connected component segmentation and color marker extraction. The results obtained are satisfactory on the dataset. Extended tests on a larger

database are foreseen in the framework of the TerraNumerica project.

\section{ACKNOWLEDGES}

The work reported in this paper has been performed as part of Cap Digital Business Cluster TerraNumerica project.

\section{REFERENCES}

[1] Luc Van Gool, Gang Zeng, Filip Van den Borre, and Pascal Müller, "Towards mass-produced building models," in PIA'0\%: Photogrammetric Image Analysis, September 2007, pp. 209-220.

[2] X. Wang, S. Totaro, F. Taillandier, A. Hanson, and S. Teller, "Recovering façade texture and microstructure from real-world images," in ECCV Texture 2002 Workshop, Copenhagen, Denmark, 2002.

[3] Sung Chun Lee and Ram Nevatia, "Extraction and integration of window in a $3 \mathrm{~d}$ building model from ground view images," IEEE Computer Vision and Pattern Recognition, vol. 02, pp. 113-120, 2004.

[4] Pascal Müller, Gang Zeng, Peter Wonka, and Luc Van Gool, "Image-based procedural modeling of facades," ACM Transactions on Graphics, vol. 26, no. 3, pp. 85-93, 2007.

[5] R. I. Hartley and A. Zisserman, Multiple View Geometry in Computer Vision, Cambridge University Press, ISBN: 0521540518, second edition, 2004.

[6] Jiebo Luo and Stephen P. Etz, "A physical modelbased approach to detecting sky in photographic images," IEEE Transactions on Image Processing, vol. 11, no. 3, pp. 201-212, 2002.

[7] Andrew C. Gallagher, Jiebo Luo, and Wei Hao, "Improved blue sky detection using polynomial model fit," in IEEE International Conference on Image Processing, ICIP'04, 2004, pp. 2367-2370.

[8] Valery Risson, Application de la Morphologie Mathématique à l'Analyse des Conditions d'éclairage des Images Couleur, Ph.D. thesis, CMM - Mines ParisTech, 2001.

[9] Serge Beucher, "Numerical residues," Image and Vision Computing, vol. 25, no. 4, pp. 405-415, 2007.

[10] Pierre Soille, Morphological Image Analysis: Principles and Applications, Springer-Verlag New York, Inc., Secaucus, NJ, USA, 2003.

\footnotetext{
${ }^{1}$ http://cmm.ensmp.fr/ hernandez/results/FacSegFromUrbanBlocks/indexFacSegFromBlocks.htm
} 